\title{
Peer Group Cohesion Promotes Prosocial Behavior
}

\author{
Wouter van den Bos ${ }^{1, *}$, Eveline A. Crone ${ }^{2}$, Rosa Meuwese ${ }^{2}, \&$ Berna Güroğlu ${ }^{2}$ \\ ${ }^{1}$ Center for Adaptive Rationality, Max Planck Institute for Human Development, Berlin, \\ Germany \\ ${ }^{2}$ Institute of Psychology, Leiden University, Leiden, the Netherlands
}

*To whom correspondence should be addressed: Wouter van den Bos, vandenbos@mpibberlin.mpg.de, tel +491758448955 


\title{
Social Structure Social Behavior
}

\begin{abstract}
Adolescence is a key period of social development at the end of which individuals are expected to take on adult social roles. The school class, as the most salient peer group, becomes the prime environment that impacts social development during adolescence. Using social network analyses, we investigated how individual and group level features are related to prosocial and social captial (generalized trust). We mapped the social networks within 22 classrooms $(\mathrm{N}=611)$ of adolescents aged between 12 and 18 years, and collected data on social behaviors towards peers. Our results indicate that individuals with high centrality show both higher levels of prosocial behavior and relational aggression. Importantly, greater social cohesion was associated with (1) reduced levels of antisocial behavior towards peers and (2) increased generalized trust. These results provide novel insights in the relationship between social structure and social behavior, and stress the importance of the school environment in the development of not only intellectual but also social capital.
\end{abstract}




\section{Introduction}

Adolescence is a transition period during which individuals become increasingly independent and take on adult roles in the society. It is also a period of significant social re-orientation ${ }^{1,2}$; there is an increase in time spent with peers and decrease in time spent with parents ${ }^{3}$, and the peer group becomes an increasingly important source of influence on adolescent behavior ${ }^{4}$. In other words, adolescence is a key period for social development and thus a decisive window of opportunity to build social capital, such as trust. Adolescent developmental trends have been successfully studied from a social information processing perspective ${ }^{5,6}$, which put an emphasis on the development of the cognitive and affective processes underlying prosocial behavior. For instance, it is well documented that during this period most individuals become more skilled and flexible in taking the perspective of others into account ${ }^{7-9}$. However, it has long been stressed that the social context in which these developmental changes unfold is critical to understanding the changes during this stage of life ${ }^{10,11}$. Yet, our knowledge of influences of the social environment on adolescent social development is still limited.

It has long been recognized that in adolescence the peer group is one of the most salient developmental ecologies ${ }^{12}$. In one line of work, the study of peer relations has focused on sociometric status, or how well liked individuals are in their peer group ${ }^{13}$. Sociometric status in a peer group -typically a school class- is based on the number of like and dislike nominations received within the peer group. Another related line of research within the peer relationship literature has focused on the concept of perceived popularity ${ }^{13-15}$. Both measures have been valuable predictors of (the development of) prosocial and antisocial behavior. In a parallel line of research, finding its roots in sociology, social network analyses were used to map the social relationships within school classes based on reports of who interacts with whom. These studies categorized adolescents' social position in the peer network as member of a smaller clique, a liaison (bridge between cliques) or an isolate (not a member of any clique) ${ }^{16}$. A handful of those studies investigated the relationship between these type of 
network measures and social behaviors in the classroom ${ }^{17-19}$, and showed that these measures predict unique patterns of social behavior, but also resemble perceived popularity ${ }^{18}$.

In sum, there is ample evidence that social position in a group is related to the displays of pro- and antisocial behavior during adolescence. However, measures of individual social position or clique membership mostly ignore the complexity and influence of larger social network structures. For instance, social networks typically exhibit various levels of connection density, clustering, hierarchy and segregation ${ }^{20}$. These structural differences in network structure, and their potential effects on social development, are not captured by nomination counts, clique membership or individual network position. For instance, it has long been acknowledged that bullying is group processes that involves bystanders ${ }^{19}$, and a recent study also showed that clique structure has an impact on the display of prosocial and aggressive behaviors beyond social position ${ }^{21}$. However, this study did not focus on the larger social structure that the clique were embedded in. In addition, like most studies, this study focused on the relationship between social structure and social behavior within the peer group, currenty not much is known about how peer group social structure (or position) relates to the development of social behavior in general. That is, it is not clear whether social behavior displayed in the peer group is context dependent or transfers to other social settings. The main goal of the current study is thus to extend previous work by using social network metrics to address these outstanding questions.

First, we will use social network analyses to quantify group levels metrics of social cohesion within each peer group. Although social cohesion plays a central role in sociological theories of social capital ${ }^{22,23}$, its relation with individual levels pro- and antisocial behaviors is not well understood. Here we investigate how social cohesion in the classroom relates to behavior towards people in- and outside the classroom. We expect that increased social cohesion is associated with increased levels of prosocial behaviors and decreased levels of anti-social behaviors. Furthermore, increased social network cohesion has been theoretically ${ }^{23}$ and analytically ${ }^{24,25}$ associated with increased trust, but to our knowledge never empirically. We therefore hypothesized that increased social cohesion is associated with increased levels 
of generalized trust (trust is general others). Trust in (unfamiliar) others is an important indicator of social capital - it has been associated with increased community engagement and higher rates of economic growth ${ }^{26,27}$. Finally, we will explore how social cohesion is related to an important, and contentious, exogenous variable that determines group structure: class size.

Second, social network analyses enable us to conduct fine-grained analyses of individuals' position in the group (i.e., measures of centrality). Some centrality measures are partly overlapping with more traditional measures of perceived popularity ${ }^{28}$, and there we expect that increased centrality would be associated with increased levels of both prosocial and antisocial behavior. However, other centrality measures capture unique network related positional information and we expect them to provide novel insights in the relation between position and social behavior.

To address these issues we collected data from 611 adolescents in 22 different classes within one school. We used peer nomination data to construct the social networks that allowed us to measure both individual position and social cohesion, and investigate their relationship to social behavior. Behavior within the peer group was based on peer-reports of individuals' prosocial (e.g., helping) and antisocial (e.g. bullying) behavior. To investigate prosocial attitudes towards general others we used an online version of the trust game ${ }^{29}$.

\section{Results}

\section{Social cohesion and social behavior}

Based on the 'most liked' peer nominations we constructed an undirected graph, where a connection between nodes was created when there was a reciprocal nomination (see Figure 2 for a representative network). Setting up the network like this is close to other social network studies that used only reciprocal friendship nominations $\left(\mathrm{cf}^{30}{ }^{30}\right.$. In addition, a large meta-analysis examining children's friendship nominations has shown that friends are significantly more likely to provide mutual liking nominations compared to non-friend dyads, unilateral friends and acquaintances ${ }^{31}$. In addition, previous studies have shown that 
reciprocal relationships are good predictors of social behaviors in adolescence ${ }^{32}$. For more information on these metrics and their relationship to existing measures such as preference and popularity see Supplementary materials.

A wide range of social attributes and behaviors was assessed based on peer nominations. For the analyses of social behavior in the classroom we focused on composite scores that describe four different types of behavior $\left.\left(\mathrm{cf.}^{33,34}\right) ; 1\right)$ prosocial behavior (cooperating and helping), 2) antisocial behavior (getting in physical fight, start arguments and bullying), 3) relational aggression (ignoring, excluding and gossiping), and 4) victimization (being excluded, ignored, bullied and gossiped about; see Methods for more details).

The first set of analyses focused on the how the overall level of social cohesion, as measured with social network metrics, is associated with frequency of different types of social behavior in the classroom. These analyses focused on three measures of social cohesion: density, diameter and cluster count (for representative networks see Figure 1). The density measure gives an indication of how many relations between individual exists relative to all possible relationships that could exist (total number edges / total possible number of edges). In this context a high density network is one where there are many reciprocal peer nominations. Diameter measure gives an indication of the distances in a network (see Figure 2). In a high diameter network there are individuals who almost never interact. On the other hand, low diameter indicates high cohesion; everybody knows each other well or is a "friend of a friend". Finally, the number of clusters is inversely related with cohesion: the more subgroups there are the less the overall cohesion of the group. Based on previous modeling work ${ }^{24,25}$ we expected that increased social cohesion is associated with increased levels of prosocial behavior both in- and outside the classroom. 

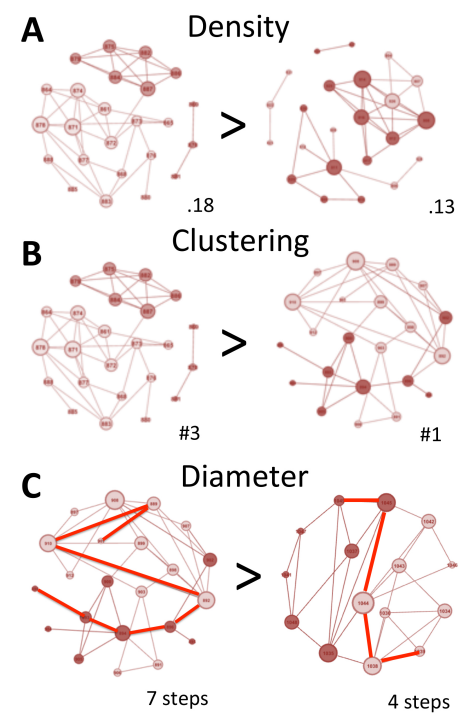

Figure 1. Illustrations of the different network metric used in our analyses based on representative classrooms from the current dataset. Each node (indicated by a circle) is a group member. The size of the nodes is associated with the total number of connections it has, and the color indicates gender (light $=$ female). The panels present examples of the different social cohesion measures. In panel A there are two networks that differ in network density. Panel B shows a network that consists of 3 clusters and one network that has only one big cluster. In panel $\mathrm{C}$ the path that is highlighted is (one of) the longest path(s) between two nodes in a network.

Frequency of social behaviors within the group was entered as dependent variable in a multiple mixed model regression with social cohesion measures, age and gender ratio as independent variables (see Table 1). The results highlight that group level measures are only associated with the level of antisocial behavior in the group. More specifically, increased amounts of antisocial behavior are associated with lower social cohesion, as measured by lower network density $(\beta=-.884, p<.02)$, and larger group sizes $(\beta=.771, p<.02)$.

Table 1. Group level: Results of multiple logistic regressions with aggregate social behavior as dependent variables

\begin{tabular}{lllll}
\hline & Prosocial & Antisocial & Relational & Victimizzation \\
\cline { 2 - 5 } Diameter & -0.123 & -0.351 & 0.074 & 0.345 \\
& $(-0.409,0.162)$ & $(-0.557,-0.144)$ & $(-0.865,0.482)$ & $(-0.006,0.695)$ \\
Clusters & -0.293 & -0.078 & -0.028 & 0.211 \\
& $(-0.645,0.06)$ & $(-0.418,0.261)$ & $(-0.388,0.332)$ & $(-0.222,0.643)$ \\
Density & -0.511 & $-0.884 *$ & 0.132 & 0.077 \\
& $(-0.978,-0.044)$ & $(-1.208,-0.56)$ & $(-0.345,0.609)$ & $(-0.497,0.65)$ \\
Gender ratio & -0.38 & 0.528 & -0.385 & 0.061 \\
Age & $(-0.681,-0.08)$ & $(0.291,0.764)$ & $(-0.692,-0.078)$ & $(-0.308,0.43)$ \\
Group size & -0.194 & $-0.213^{*}$ & -0.047 & -0.177 \\
& $(-0.429,0.041)$ & $(-0.399,-0.027)$ & $(-0.287,0.193)$ & $(-0.465,0.112)$ \\
\hline
\end{tabular}

All regression models included age, group size, gender ratio ( $1=$ all boys), and individual frequencies of social behaviors as independent variables. Individual unstandardized $\beta$ 's are reported (95\% confidence interval in parentheses) Note. * $p<.05 ;{ }^{* *} p<.01$ (FDR corrected) 
Next, we considered the effect of social network structure on generalized trust.

Generalized trust is the trust displayed in interactions with unfamiliar others and is not based upon previous interactions or information acquired about that individual. We used an online version of the binary choice Trust Game ${ }^{29,35,36}$ to assess generalized trust (see Figure 2). Before the participants played the trust game they were instructed that these games would have real (monetary) consequences for both players and that one of the games would be randomly picked at the end of the experiment to determine their pay-off. The identity of both players was kept completely anonymous; the only information that was revealed was that the other person was of the same age and gender as the participant (see supplement for more details).
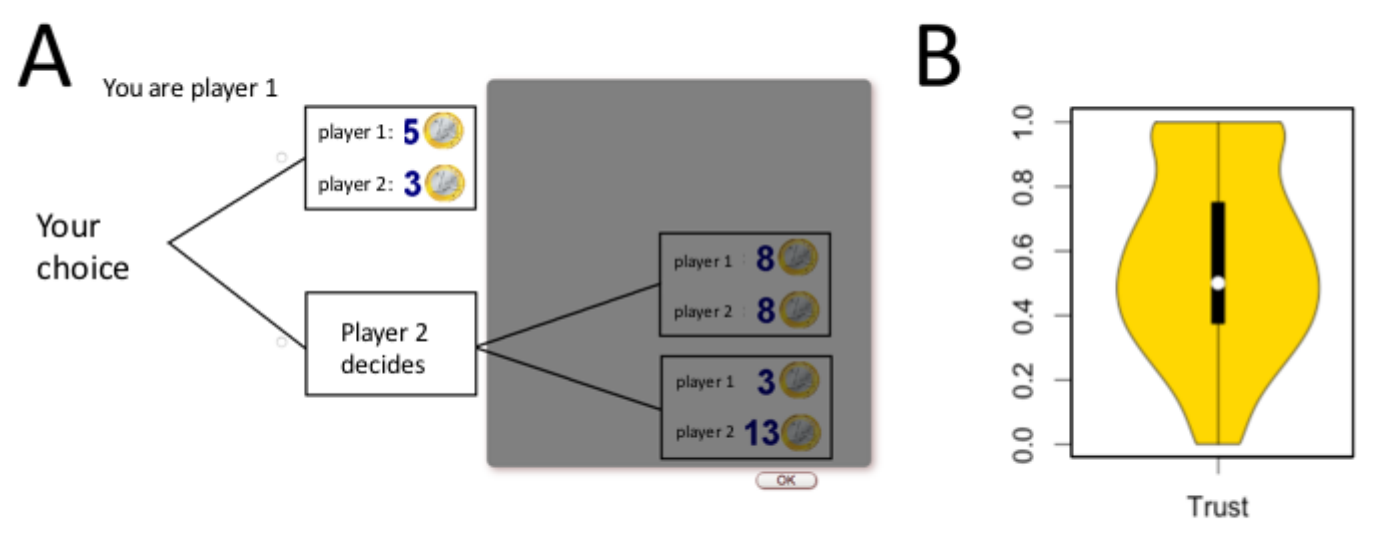

Figure 2. The Trust Game. A) When the participant was the first player she could decide to either trust or not trust the other person. The possible outcomes for trusting where shaded to indicate the role of the participant but still clearly visible. B) Distributions of percentages of trust choices, white circle is the population mean.

The percentage of trust choices was entered as dependent variable in a multiple mixed model regression analysis with the network positions, age and gender as independent variables.

Consistent with previous findings ${ }^{37}$, we found that boys show more trust than girls $(\beta=-.149$, $p<.005)$. More importantly, the overall levels of social cohesion were associated with levels of trust (see Table 2). That is, increased number of clusters and larger diameter, both indicating lower social cohesion, were associated with lower levels of trust $(\beta=-.302, p$ $<.001$ and $\beta=-.239, p<.02$ respectively). 
Table 2. Group level statistics: Results of multiple logistic regressions with generalized trust dependent variable

\begin{tabular}{ll}
\hline & Trust \\
\cline { 2 - 2 } Diameter & $-.239^{*}$ \\
& $(-.463,-.015)$ \\
Clusters & $-.302^{* * *}$ \\
& $(-.470,-.135)$ \\
Density & -.222 \\
& $(-.461, .016)$ \\
Gender ratio & -.017 \\
& $(-.296, .263)$ \\
Age & $.234^{* *}$ \\
& $(.084, .383)$ \\
Group size & -.074 \\
& $(-.007, .012)$ \\
Constant & $.326^{* * *}$ \\
& $(.209, .445)$ \\
\hline All regression models included age, group size, \\
gender ratio (1 = all boys), and individual \\
frequencies of social behaviors as independent \\
variables. Individual unstandardized $\beta$ 's are reported \\
(95\% confidence interval in parentheses) Note. * $\mathrm{p}$ \\
$<.05 ;{ }^{* *} \mathrm{p}<.01{ }^{* * *} \mathrm{p}<.001$ (FDR corrected) \\
\hline
\end{tabular}

Group size \& social behavior: Exploratory Mediation Analysis

Group size is a unique variable given that this is one of the few exogenously induced variables that is, in principle, controllable. Interestingly we found that that group size is negatively correlated with cohesion. The larger the group, the less dense the network is, and the more clusters it has (see Table S3). Taken together our data show that (1) increased group size is related to a reduction of cohesion, and in turn that (2) reduced cohesion is related to both a reduction of prosocial behavior and an increase in antisocial behavior (Table 1 and 2). We next explored this suggested causal set of relations using mediation analyses. Specifically, our data suggests that 1) increased group size reduces the density of the connections which in turn leads to more antisocial behavior, and 2) increased group size may lead to an increase in the number of clusters and this in turn leads to a reduction in generalized trust (see Figure 3).

In the first mediation model (Figure 3A) we tested whether the influence of group size on antisocial behavior was mediated by network density. This mediation analyses revealed that the average causal mediation effect (ACME) of network density on antisocial behavior was significantly different from zero (ACME; $\delta=.01,95 \% \mathrm{CI}=[.003, .035], p$ $<.01)$. As expected the direct effect of group size remained non-significant (average direct 
effect, ADE: $\zeta=.018,95 \% \mathrm{CI}=[-.006, .037], p=.16)$. This suggests that, although there is no significant positive relation between group size and antisocial behavior, there is a measureable indirect effect of group size on antisocial behavior that is through its influence on density of the network connections in a classroom (where higher density indicates increased social cohesion).

A

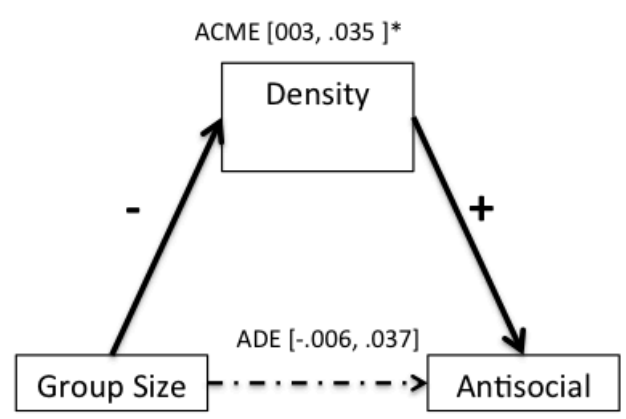

B

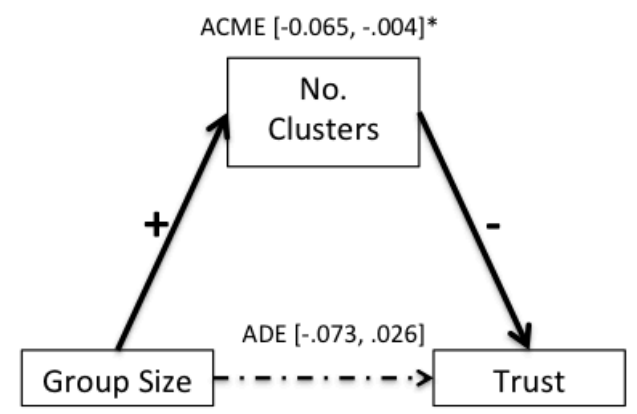

Figure 3. Schematic representations of the mediation models.

In the second mediation model (Figure 3B), we also first tested the relation between group size and trust in a model in a simple regression model. As expected, we did find a negative relationship $(\beta=-.05, t=-2.535, p<.03)$, suggesting that there is less trust in larger groups. The subsequent mediation analyses revealed that the average causal mediation effect of number of clusters was significantly different from zero (ACME; $\delta=-.026,95 \% \mathrm{CI}=[-$ $.065,-.004], p<.04$; see Figure 3B), whereas the average direct effect was not (ADE: $\zeta=-$ $.023,95 \% \mathrm{CI}=[-.073, .026], p=.36)$. This suggests that our current data are indeed consistent with the hypothesis that the effect of group size on generalized trust is mediated by changes in the number of clusters in the network (where more clusters indicate less cohesion).

\section{Social position and social behavior}

Finally, we used social network metrics as individual difference measures reflecting social position. The individual network metrics reflect different aspects of influence and importance within the network. We focused on three standard social network metrics (eigenvector-, 
betweenness- and closeness centrality) to see how individual position within the social network is related to specific types of behavior (see Figure 4). Eigenvector centrality is an indicator of the importance of individuals in the network that takes into account the number of connections an individual has, and the quality of the nodes it is connected to (in turn determined by number of connections). In other words, high eigenvector indicates a high level of influence rather than simply having many connections. Second, betweenness centrality gives an indication of how important a person is for the transmission of information through different parts of the network. Third, closeness centrality indicates whether someone is in the center or the fringe of the network. Someone with high closeness centrality is in close connection with those at the top and well as the bottom of the hierarchy. Given that eigenvector centrality is conceptually related to the perceived popularity ${ }^{28}$, we expected that they would be associated with increased levels of both prosocial and antisocial behavior ${ }^{14}$. However, given that the other metrics also capture unique network related variance we expected them to provide novel insights in the relation between position and social behavior.
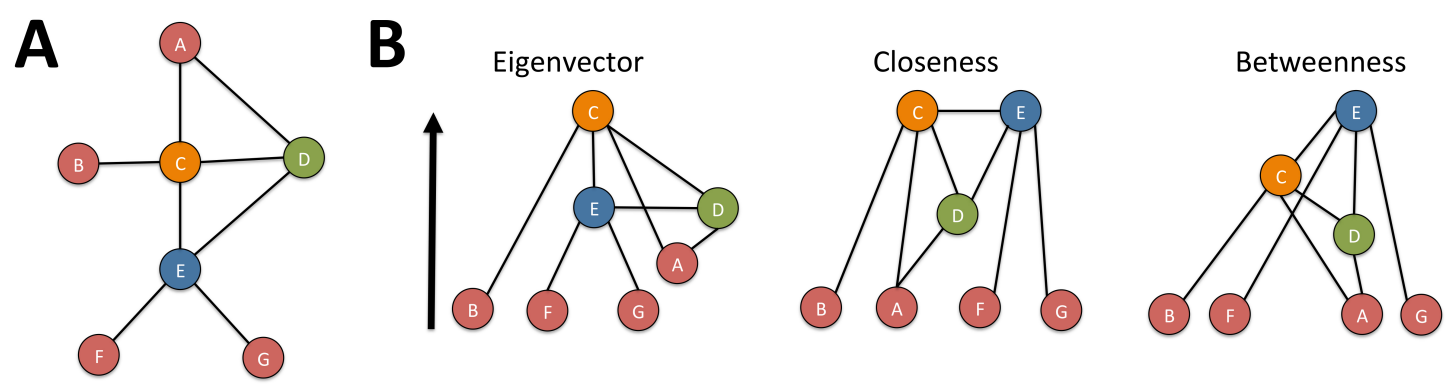

Figure 4. Panel A: an example of a hypothetical social network illustrating the individual level metrics. Panel B: the same network is restructured in a hierarchy such that the node with the highest relevant centrality measure is on top.

The first set of analyses focused on the how centrality measures were associated with peerreported individual social behavior in the classroom. The same four types of social behaviors as used above (list here) were entered as dependent variables in separate multiple mixed model regression analyses with the network positions, age and gender as independent variables. This allowed us to find the unique variance associated with the network measures 
and social behaviors. The results show that eigenvector centrality is strongly associated with several aspects of social behavior in the classroom (see Table 3).

In line with previous findings, high eigenvector centrality was associated with both increased prosocial behavior and increased relational aggression $(\beta=2.54, p<.001$ and $\beta=.129, p<.008$ respectively). Also in line with expectations, those individuals at the top of the social network were the least likely to be victimization $(\beta=-.325, p<.001)$. In sum, the eigenvector centrality measures behaves similar to perceived popularity measures (but see Supplementary Results), firmly embedding our edge measure (reciprocal likes) into the existing literature. Betweenness centrality on the other hand, was related to lower levels of relational aggression $(\beta=-.09, p<.02)$. Closeness centrality did not show any significant relation with classroom behavior. Finally, in line with previous work, girls showed more prosocial behavior $(\beta=-1.93, p<.001)$, as well as more relational aggression $(\beta=-.203, p$ $<.001)$, than boys. Boys, on the other hand, displayed more antisocial behavior $(\beta=.253, p$ $<.001)$. Finally, we investigated the relationship between social position and generalized trust. However, the results showed that none of the individual network metrics were associated with generalized trust (Table S4).

Table 3. Results of multiple logistic regressions with social behaviors as dependent variables

\begin{tabular}{|c|c|c|c|c|}
\hline & Prosocial & Antisocial & Relational & Victimization \\
\hline Eigenvector & 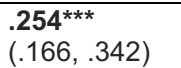 & $\begin{array}{l}.043 \\
(-.036, .121)\end{array}$ & $\begin{array}{l}.129^{\star *} \\
(.048, .210)\end{array}$ & $\begin{array}{l}-.325^{\star * *} \\
(-.394,-.256)\end{array}$ \\
\hline Betweenness & $\begin{array}{l}.034 \\
(-.048, .116)\end{array}$ & $\begin{array}{l}-.056 \\
(-.130, .012)\end{array}$ & $\begin{array}{l}-.090^{*} \\
(-.166,-.015)\end{array}$ & $\begin{array}{l}-.045 \\
(-.109, .020)\end{array}$ \\
\hline Closeness & $\begin{array}{l}-.007 \\
(-.093, .080)\end{array}$ & $\begin{array}{l}.010 \\
(-.067, .088)\end{array}$ & $\begin{array}{l}-.007 \\
(-.087, .073)\end{array}$ & $\begin{array}{l}.012 \\
(-.057, .080)\end{array}$ \\
\hline Age & $\begin{array}{l}-.014 \\
(-.095, .066)\end{array}$ & $\begin{array}{l}.008 \\
(-.064, .080)\end{array}$ & $\begin{array}{l}.007 \\
(-.067, .081)\end{array}$ & $\begin{array}{l}-.011 \\
(-.075, .053)\end{array}$ \\
\hline Gender & $\begin{array}{l}-.193^{* * *} \\
(-.272,-.114)\end{array}$ & $\begin{array}{l}.253^{* * *} \\
(.181, .324)\end{array}$ & $\begin{array}{l}-.203^{* * *} \\
(-.276,-.130)\end{array}$ & $\begin{array}{l}-.045 \\
(-.107, .017)\end{array}$ \\
\hline Constant & $\begin{array}{l}.053 \\
(-.026, .131)\end{array}$ & $\begin{array}{l}-.022 \\
(-.092, .048)\end{array}$ & $\begin{array}{l}-.013 \\
(-.086, .059)\end{array}$ & $\begin{array}{l}-.101^{* *} \\
(-.163,-.038)\end{array}$ \\
\hline \multicolumn{5}{|c|}{$\begin{array}{l}\text { Logistic regression models included age, gender }(1=\text { male, } 0=\text { female) and individual } \\
\text { network level metrics as independent variables. Individual unstandardized } \beta \text { 's are } \\
\text { reported }\left(95 \% \text { confidence interval in parentheses) Note. }{ }^{*} p<.05 ;{ }^{* *} p<.01{ }^{* * *} p<.001\right. \\
\text { (FDR corrected). }\end{array}$} \\
\hline
\end{tabular}




\section{Discussion}

The main purpose of this study was to uncover the relation between social structure and adolescents' social behavior by utilizing social network analyses to identify individual and contextual characteristics related to prosocial and antisocial behavior. The social network analyses allowed us to separate effects with respect to the analytic level where they occurred: 1) the group level with measures describing social cohesion, and 2) the individual level with factors associated with each person's position in a network. Our novel approach enabled us to extend previous findings in three ways. First, we were able to investigate the relation between group level features and social behavior. Second, we were able to investigate to what extend the link between network characteristics and social behavior generalizes towards people outside the network, and contribute to social capital. Third, the social network analyses allowed a more fine-grained analysis of the relationship between social position and social behavior. Taken together, our results provide evidence for the influence of social position and structure on behavior in- and outside the classroom. In the discussion we will first address our conclusions regarding social behavior within the classroom followed by behavior outside the classroom.

Consistent with previous studies we found that individuals who are central in the network structure show both increased prosocial behavior, as well as increased relational aggression ${ }^{14,17,18}$. It is important to note that individuals with high eigenvector centrality did not necessarily engage in antisocial behavior (such as fighting), which might lead to being disliked, but in relational aggression, which is more likely to indicate manipulative behavior in interpersonal relationships and thus increase one's position in the group. These findings underline the conclusions from previous studies that taking a central role in the network is not only achieved by being nice ${ }^{14}$, and validate that the centrality measures in this network pick up relevant social relations (for further comparisons with traditional measures see Supplementary Results). On the other hand, note also that those with a high betweenness centrality - individuals who have reciprocal likes with individuals from different parts of the 
network- stand out by showing less relational aggression. This novel finding suggests that it is possible to occupy a significant role in the network without relying on relational aggression (even refraining from it). Indeed, our analyses also revealed that betweenness centrality predicted how much people liked you, but not how popular you are (See Supplemental Results).

Importantly, we also found that social cohesion was associated with reduced levels of antisocial behavior in the classroom. In addition, our exploratory mediation analyses suggested that social cohesion partly mediates the effect of group size on antisocial behavior. This relation between group size and social cohesion may explain mixed reports about the relation between class size and bullying behavior. For instance, O'Moore and colleagues reported that smaller classes show less bullying ${ }^{38}$, whereas others have failed to find this relationship ${ }^{39,40}$. Thus, class size may not be directly related to the amount of antisocial behavior but via its effect on the social structure of the classroom. Indeed, several studies have shown that antisocial children are more popular in hierarchical as compared to egalitarian classrooms ${ }^{18,41,42}$. Our results underline that it is crucial to understand the determinants of the social structure in the classroom in order to contribute to interventions programs aimed at reducing antisocial behavior. In addition, the mediation analyses suggest that class size may be an important tool to increase social cohesion.

Finally, we investigated the impact of the social network structure on generalized trust. On the individual level none of the network metrics predicted the level of trust in unknown others, but, in line with our hypothesis, we found that higher levels of social cohesion were associated with increased generalized trust. Such an effect is also in line with sociological and economical theories about the role of social structure on social capital ${ }^{22,23}$. For instance, recent social network analyses have shown how network cohesion could contribute to the emergence and sustainability of cooperative behavior ${ }^{43}$. These studies show that more effective communication, and therefore social control (punishment), in cohesive networks can lead to more cooperation and trust ${ }^{44,45}$. In addition, the theory of social capital suggests that the trust, or social capital, built up in one context is transferable to another ${ }^{26}$. 
This notion of transfer is partly supported by our finding that there was a trending relationship between cohesion and the amount of reported prosocial behavior. To conclude, this implies that the classroom may be a valuable source of social capital ${ }^{26}$, regardless of the social position of an individual. We already pointed out that class size may play an important role in increasing cohesion, and thus be a focal point for policy, but earlier research also indicated that there might be an important role for the schools and teachers ${ }^{46}$. For instance, one study showed that promoting the classroom as a unit in school might have positive impact on stability of social relations and scholarly engagement of pupils ${ }^{47}$. Our work suggests that such interventions may also contribute to increasing social capital.

The current study does not come without limitations. The most obvious limitation is the cross-sectional design of our study, whereby causal interpretations (directionality) of underlying mechanisms remain speculative. Longitudinal studies are necessary to identify developmental trajectories of social behavior that can help crystallize the reciprocal influence of social structure and social behavior. Interestingly, one longitudinal study suggests that in early to mid-adolescence the social networks are rather stable, at least over the period of one year ${ }^{16}$. One of the most interesting starting points would therefore be to examine the formation of a new class at the beginning of secondary school. This would allow grasping how social behavior contributes to the formation of the network structure and later how that structure starts to co-shape social behavior.

The current findings provide a promising starting point for studying the impact of social network structure on the development of social behavior in adolescence. With regards to possible policy implications it is interesting to highlight the effects of group size. The main focus of discussion about sizes has been the teacher to pupil ratio and the effect of group size on the academic performance of the pupils. Regardless which stance is taken in that debate, the current results suggest that there is another argument for limiting group sizes: social capital $^{48}$. To conclude, it is important for future studies to examine how these network metrics relate to and reflect the impact of specific school programs that are aimed at increasing prosocial behavior and class cohesion, such as anti-bullying programs (e.g., good 
Social Structure Social Behavior

behavior game ${ }^{49}$ ) and democracy education ${ }^{50}$. The network metrics may serve as short-term indicators of the success of these interventions. Crucially, this line of research should next include the mapping of these measures onto real-world prosocial behaviors such as volunteering. 


\section{Methods}

\section{Participants}

We recruited 22 classes from a single school in the Netherlands resulting in a total of 611 (321, female) participants, with a mean age of $14.8(S D=1.49)$ years. The classes ranged from the first grade (12-13 years) to the sixth grade (17-18 years) of high school. Two classes were excluded for further analyses because they both consisted of two mixed classes that changed in composition over time and both differed significantly in size $(\mathrm{N}=55$ and $\mathrm{N}=60$ respectively); the mean class size after exclusion was $27.7(S D=7.7)$ and total $\mathrm{N}=496$. Most participants were of Dutch origin (84\%), as were most of their parents (70\%); other participants were of various origins around the globe (both European and non-European). Participants were recruited and data was collected in March and April 2011 from a local secondary school in Wassenaar, an affluent suburb of the Hague, the Netherlands.

\section{Measures}

\section{$\underline{\text { Peer Nominations \& Social Behavior }}$}

A wide range of social attributes and behaviors was assessed based on peer nominations. These included questions about likeability (i.e., 'Who do you like the most?' and 'Who do you like the least?') and popularity (i.e., 'Who is most popular in the class?' and 'Who is least popular in the class?'), as well as overt behaviors such as helping, bullying and gossiping (see Appendix for the complete list of items). Participants could nominate an unlimited number of peers for each category but self-nominations were not allowed. The number of nominations of certain type of behavior a group member received was interpreted as a proxy for how often an individual displays this behavior within the social network. For the analyses of social behavior we focused on composite scores that describe four different types of behavior (cf $33,34)$; 1) prosocial behavior (cooperating and helping), 2) antisocial behavior (getting in physical fight, start arguments and bullying), 3) relational aggression (ignoring, excluding and gossiping), and 4) victimization (being excluded, ignored, gossiped about and bullied). However, for exploratory purposes we have also included item level regressions in the 
supplementary results. We have used the nominations for the item 'who do you like most' to construct the social networks for each of the classrooms. Finally, age and gender were included in the individual level models, and on the group level we have included class size, mean age and gender ratio in all analyses. Note that both age and gender are the focus of another studie (in preparation) and that these variables were essentially included as possible variables to see how the unique variance of the network measures is related to the beahvioral outcomes. Therefore these effects will not be further discussed here, but will be examined in a separate manuscript.

\section{$\underline{\text { Social Network Analyses }}$}

The network structure of each group, and individual node properties (eigenvector centrality, betweenness and closeness) were analyzed using the ipgraph package (version 1.0; http://igraph.org) for $\mathrm{R}^{51}$, and visualized in Gephi ${ }^{52}$. We used three standard centrality metrics to indicate individual positions within the social network: eigenvector, betweenness and closeness centrality. Three network level metrics were used as indicators for social cohesion: density, diameter and number of clusters. Clusters within a network were determined using the clusters algorithm based on edge betweenness ${ }^{53}$ provided by the igraph package. Further details about these metrics are described below.

\section{Individual Level Metrics}

We investigated three standard social network metrics (eigenvector-, betweenness- and closeness centrality) to see how individual position within the social network is related to specific types of behavior (see Figure 1). Eigenvector centrality is an indicator of importance of individuals in the network as it takes into account the number and quality of connections an individual has, where the quality of a connected node is measured by how many connections that node has (see Figure 1). In this respect, eigenvector centrality is often seen as a measure of importance. Because this measure takes the larger structure of the network into account it gives a richer account of how important someone is within the network compared to other sociometric measures based on the number of counts such as degree centrality or absolute 
differences (e.g. likes - dislikes). Second, betweenness centrality gives an indication of how important a person is for the transmission of information through the network. Betweenness is calculated by dividing the number of shortest paths between all pairs of nodes in the network that pass through the specific node divided by the total number of shortest paths in the network ${ }^{54}$. People with high betweenness centrality can be seen as gatekeepers between different clusters in the network. Third, closeness centrality indicates whether someone is in the center or the fringe of the network. Closeness is based on the sum of the shortest paths between a node and all other nodes ${ }^{55}$. Someone with high closeness centrality is in close connection with those at the top and well as the bottom of the hierarchy. In sum, the social network metrics combine the advantage of continuous measures as used in earlier sociometrics (e.g., popularity) with different social network categories as used in previous social network analyses.

\section{Experimental Procedures}

Informed consent was obtained from the school principal and the parents of participants. All participants were tested in their own classroom as part of a larger study accompanied by four trained experimenters. The first half of the testing session consisted of questionnaires measuring different aspects of development, such as psychosocial functioning, social behavior, and peer relationships, followed by eight different economic games including the trust game used in the current study. Finally, all participants completed a short cognitive capacity test. Each testing session lasted approximately $60 \mathrm{~min}$. Only four groups had missing data of maximally one participant who happened to be absent on the day of testing.

Before the testing session started participants were encouraged to ask questions. It was emphasized that participation was voluntary and it was ensured that all data would be handled confidentially and anonymously. The first screen that was presented before the economic games provided a reminder that the participants were playing the allocation games for real money and that at the end of data collection one person within every class would be randomly chosen to receive the money he or she earned in the four games. Each coin in the game was worth $€ 1$. Two weeks after testing the experimenters returned to the schools to give 
one participant in each class their earnings; participants received $€ 5$ on average. All procedures were approved by the local ethics committee.

\section{Statistical Procedures}

For all individual behavior multiple hierarchical regression models were used in order to take into account the structure of the data (subjects nested in classrooms). The lmer function of the lme4 library in R was used to estimate the mixed models ${ }^{56}$, with variable intercepts and fixed slopes per classroom. Note that fixed slopes models showed superior goodness-of-fit compared to variable slope models based on the standard Bayesian model comparison indicators. Degrees of freedom and $p$ values for mixed effects models were calculated with the lmerTest library in R, using Satterthwaite's approximation ${ }^{57}$. Finally all reported $p$-values associated with the regression models are adjusted for multiple comparisons using false discovery rates ${ }^{58}$.

Group level analyses were performed to obtain the social cohesion measures. To examine how cohesion was related to social behavior within the classroom we calculated for each of the social behavior categories the total number of individuals within the classroom that were reported to show this type of behavior. This total number was transformed to a ratio by dividing it by the total number of individuals in the classroom. Next, we calculated the average level of generalized trust within a social network. Finally, given that the diameter and number of clusters are related to group size, we also included total group size in all the group level analyses.

Mediation analyses were performed using the mediation package in $\mathrm{R}^{59}$, using 10000 quasi-Bayesian Monte Carlo simulations to estimate confidence intervals, and White's heteroskedasticity-consistent estimator for the covariance matrix from the sandwich package ${ }^{60}$. 
Social Structure Social Behavior

\section{Acknowledgements}

This research was supported by a grant from the European Research Council (Crone) and a Open Reseach Area gant (ID 176, van den Bos). The authors would like to thank Barbara Braams, Sabine Peters, Anneke de Gier, Jorien van Hoorn, Sandy Overgaauw, Merel Schrijver, Erik de Water, and Dafna Windhorst for their assistance with data collection and Raoul Grasman for his assistance in task development. 


\section{Figure Legends}

Figure 1. Panel A: an example of a hypothetical social network illustrating the individual level metrics. Panel B, the same network is restructured in a hierarchy such that the node with the highest relevant centrality measure is on top.

Figure 2. The Trust Game. A) The participant in the role of the first player could decide to either trust or not trust the other person. The possible outcomes for trusting where shaded to indicate the role of the participant but the outcomes were still clearly visible. B) Distributions of percentages of trust choices, white circle is the population mean.

Figure 3. Schematic representations of the mediation models.

Figure 4. Illustrations of the different network metric used in our analyses based on representative classrooms from the current dataset. Each node (indicated by a circle) is a group member. The size of the nodes is associated with the total number of connections it has, and the color indicates gender (light $=$ female). The panels present examples of the different social cohesion measures. In panel A there are two networks that differ in network density. Panel B shows a network that consists of 3 clusters and one network that has only one big cluster. In panel $\mathrm{C}$ the path that is highlighted is (one of) the longest path(s) between two nodes in a network. 


\section{References}

1. Forbes, E. E. \& Dahl, R. E. Pubertal development and behavior: Hormonal activation of social and motivational tendencies. Brain Cogn. 72, 66-72 (2010).

2. van den Bos, W. Neural mechanisms of social reorientation across adolescence. $J$. Neurosci. 33, 13581-2 (2013).

3. Csikszentmihalyi, M., Larson, R. \& Prescott, S. The ecology of adolescent activity and experience. J. Youth Adolesc. 6, 281-94 (1977).

4. Steinberg, L. D. \& Hill, J. P. Patterns of family interaction as a function of age, the onset of puberty, and formal thinking. Dev. Psychol. 14, 683-684 (1978).

5. Dodge, K. A. \& Crick, N. R. Social Information-Processing Bases of Aggressive Behavior in Children. Personal. Soc. Psychol. Bull. 16, 8-22 (1990).

6. Blakemore, S.-J. \& Mills, K. L. Is Adolescence a Sensitive Period for Sociocultural Processing? Annu. Rev. Psychol. 65, 187-207 (2014).

7. Eisenberg, N., Cumberland, A., Guthrie, I. K., Murphy, B. C. \& Shepard, S. a. Age changes in prosocial responding and moral reasoning in adolescence and early adulthood. J. Res. Adolesc. 15, 235-260 (2005).

8. van den Bos, W., van Dijk, E., Westenberg, M., Rombouts, S. a R. B. \& Crone, E. a. Changing brains, changing perspectives: the neurocognitive development of reciprocity. Psychol. Sci. a J. Am. Psychol. Soc. / APS 22, 60-70 (2011).

9. Burnett, S., Sebastian, C., Cohen Kadosh, K. \& Blakemore, S. J. The social brain in adolescence: Evidence from functional magnetic resonance imaging and behavioural studies. Neurosci. Biobehav. Rev. 35, 1654-1664 (2011).

10. Nelson, E. E., Jarcho, J. M. \& Guyer, A. E. social re-orientation and brain development: an expanded and updated view. Dev. Cogn. Neurosci. 17, 118-127 (2015).

11. Bronfenbenner, U. The ecology of human development. experiments by nature and desing. (1979).

12. Eder, D. The Cycle of Popularity : Interpersonal Relations Among Female Adolescents. Sociol. Educ. 58, 154-165 (1985).

13. Cairns, R. B. Sociometry, psychometry, and social structure: A commentary on six recent studies of popular, rejected, and neglected children. Merrill. Palmer. Q. 29, 429-438 (1983).

14. Cillessen, A. H. N. \& Rose, A. J. Understanding Popularity in the Peer System. Curr. Dir. Psychol. Sci. 14, 102-105 (2005).

15. Cillessen, A. H. N. \& Mayeux, L. From censure to reinforcement: developmental changes in the association between aggression and social status. Child Dev. 75, 14763

16. Ennett, S. T. \& Bauman, K. E. Adolescent Social Networks: School, Demographic, and Longitudinal Considerations. J. Adolesc. Res. 11, 194-215 (1996).

17. Cairns, R. B., Cairns, B. D., Neckerman, H. J., Gest, S. D. \& Gariépy, J. L. Social Networks and Aggressive Behavior: Peer Support or Peer Rejection? Dev. Psychol. 24, 815-823 (1988).

18. Farmer, T. W. \& Rodkin, P. C. Antisocial and Prosocial Correlates of Classroom Social Positions: The Social Network Centrality Perspective. Soc. Dev. 5, 174-188 (1996).

19. Huitsing, G. \& Veenstra, R. Bullying in classrooms: participant roles from a social network perspective. Aggress. Behav. 38, 494-509 (2012).

20. McFarland, D. A., Moody, J., Diehl, D., Smith, J. A. \& Thomas, R. J. Network Ecology and Adolescent Social Structure. Am. Sociol. Rev. 79, 1088-1121 (2014).

21. Pattiselanno, K., Dijkstra, J. K., Steglich, C., Vollebergh, W. \& Veenstra, R. Structure Matters: The Role of Clique Hierarchy in the Relationship Between Adolescent Social Status and Aggression and Prosociality. J. Youth Adolesc. 44, 2257-2274 (2015). 
22. Coleman, J. S. Social Capital in the Creation of Human Capital. Am. J. Sociol. 94, S95 (1988).

23. Putnam, R. R. D. Bowling Alone: America's Declining Social Capital. J. Democr. 6, 65-78 (1995).

24. Allcott, H., Karlan, D. \& Möbius, M. Community size and network closure. Am. Econ. Revi 97, 80-85 (2007).

25. Buskens, V. The social structure of trust. Soc. Networks 20, 265-289 (1998).

26. Fukuyama, F. Trust: The Social Virtues and the Creation of Prosperity.

27. Knack, S. \& Keefer, P. Does Social Capital Have an Economic Payoff? A CrossCountry Investigation. Q. J. Econ. 112, 1251-1288 (1997).

28. Bonacich, P. Power and centrality: A family of measures. Am. J. Sociol. (1987).

29. Berg, J., Dickhaut, J. \& McCabe, K. Trust, Reciprocity, and Social History. Games Econ. Behav. 10, 122-142 (1995).

30. Add Health. Add Health The National Longitudinal Study of Adolescent to Adult Health. Available at: http://www.cpc.unc.edu/projects/addhealth/design.

31. Newcomb, A. \& Bagwell, C. Children's friendship relations: A meta-analytic review. Psychol. Bull. 117, 306-347 (1995).

32. Burnett Heyes, S. et al. Relationship Reciprocation Modulates Resource Allocation in Adolescent Social Networks: Developmental Effects. Child Dev. 86, 1489-506 (2015).

33. Güroğlu, B., Haselager, G. J. T., van Lieshout, C. F. M. \& Scholte, R. H. J. Antagonists in Mutual Antipathies: A Person-Oriented Approach. J. Res. Adolesc. 19, 35-46 (2009).

34. Güroğlu, B., van Lieshout, C. F. M., Haselager, G. J. T. \& Scholte, R. H. J. Similarity and complementarity of behavioral profiles of friendship types and types of friends: Friendships and psychosocial adjustment. J. Res. Adolesc. 17, 357-386 (2007).

35. van den Bos, W., Westenberg, M., van Dijk, E. \& Crone, E. a. Development of trust and reciprocity in adolescence. Cogn. Dev. 25, 90-102 (2010).

36. Güroğlu, B., van den Bos, W. \& Crone, E. a. Sharing and giving across adolescence: an experimental study examining the development of prosocial behavior. Front. Psychol. 5, 291 (2014).

37. Rau, H. A. Trust and Trustworthiness: A Survey of Gender Differences. Psychol. Gend. Differ. (2011).

38. Q'Moore, A. M., Kirkham, C. \& Smith, M. Bullying behaviour in Irish schools: A nationwide study. Irish J. Psychol. 18, 141-169 (1997).

39. Olweus, D. Bullying at School: Basic Facts and Effects of a School Based Intervention Program. J. Child Psychol. Psychiatry 35, 1171-1190 (1994).

40. Scheithauer, H., Hayer, T., Petermann, F. \& Jugert, G. Physical, verbal, and relational forms of bullying among German students: age trends, gender differences, and correlates. Aggress. Behav. 32, 261-275 (2006).

41. Garandeau, C. F., Ahn, H.-J. \& Rodkin, P. C. The social status of aggressive students across contexts: The role of classroom status hierarchy, academic achievement, and grade. Dev. Psychol. 47, 1699-1710 (2011).

42. Ahn, H.-J., Garandeau, C. F. \& Rodkin, P. C. Effects of Classroom Embeddedness and Density on the Social Status of Aggressive and Victimized Children. J. Early Adolesc. 30, 76-101 (2010).

43. Ostrom, E. Ostrom, E. 1990. Governing the Commons: The Evolution of Institutions for Collective Action. (1990).

44. Lippert, S. \& Spagnolo, G. Networks of relations and Word-of-Mouth Communication. Games Econ. Behav. 72, 202-217 (2011).

45. Ali, S. \& Miller, D. Enforcing cooperation in networked societies. Unpubl. Pap. (2013).

46. Patrick, H., Anderman, L. \& Ryan, A. Social motivation and the classroom social environment. in Goals, goal structures, and patterns of adaptive learning. 85-108 (2002).

47. Neckerman, H. The stability of social groups in childhood and adolescence: The role 
of the classroom social environment. Soc. Dev. (1996).

48. Durlak, J. A., Weissberg, R. P. \& Pachan, M. A Meta-Analysis of After-School Programs That Seek to Promote Personal and Social Skills in Children and Adolescents. Am. J. Community Psychol. 45, 294-309 (2010).

49. Kellam, S. G. et al. The good behavior game and the future of prevention and treatment. Addict. Sci. Clin. Pract. 6, 73-84 (2011).

50. Edelstein, W. Education for Democracy: reasons and strategies. Eur. J. Educ. 46, $127-$ 137 (2011).

51. Core Team, R. R: A language and environment for statistical computing. (2015).

52. Bastian, M., Heymann, S. \& Jacomy, M. Gephi: an open source software for exploring and manipulating networks. ICWSM (2009).

53. Newman, M. \& Girvan, M. Finding and evaluating community structure in networks. Phys. Rev. E 69, 26113 (2004).

54. Freeman, L. A set of measures of centrality based on betweenness. Sociometry (1977).

55. Sabidussi, G. The centrality index of a graph. Psychometrika 31, 581-603 (1966).

56. Bates, D., Mächler, M., Bolker, B. \& Walker, S. Fitting Linear Mixed-Effects Models using lme4. 51 (2014).

57. Kuznetsova, A., Brockhoff, P. \& Christensen, R. Package 'ImerTest'. (2013).

58. Author, T., Benjamini, Y., Hochberg, Y. \& Benjaminit, Y. Controlling the False Discovery Rate: A Practical and Powerful Approach to Multiple Controlling the False Discovery Rate: a Practical and Powerful Approach to Multiple Testing. Source J. R. Stat. Soc. Ser. B J. R. Stat. Soc. Ser. BMethodological) J. R. Stat. Soc. B 57, 289-300 (1995).

59. Tingley, D., Yamamoto, T., Hirose, K., Keele, L. \& Imai, K. Mediation: R package for causal mediation analysis. (2014).

60. Zeileis, A. Object-oriented computation of sandwich estimators. (2006).

61. Gest, S. D., Graham-Bermann, S. A. \& Hartup, W. W. Peer Experience: Common and Unique Features of Number of Friendships, Social Network Centrality, and Sociometric Status. Soc. Dev. 10, 23-40 (2001). 


\section{Supplement}

1) Which children from the class do you like the most?

2) Which children from the class do you like the least?

3) Which children from the class are the most popular?

4) Which children from the class are the least popular?

5) Which children from the class are good cooperators? (P)

6) Which children from the class often help others? (P)

7) Which children from the class ignore others? (R)

8) Which children from the class are ignored by others? (V)

9) Which children from the class are shy?

10) Which children from the class get in physical fights with others? (A)

11) Which children from the class gossip about other children? (R)

12) Which children from the class are gossiped about? (V)

13) Which children from the class exclude others? (R)

14) Which children from the class are excluded? (V)

15) Which children from the class get into arguments with others? (A)

16) Which children from the class bully others? (A)

17) Which children from the class are being bullied? (V)

$\mathrm{P}=$ prosocial, $\mathrm{R}=$ relational aggression, $\mathrm{A}=$ anti social behavior, $\mathrm{V}=$ victimized 
Table S1 Correlation matrix for behavior in the classroom.

\begin{tabular}{|c|c|c|c|c|c|c|c|c|c|c|c|c|}
\hline & 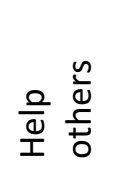 & 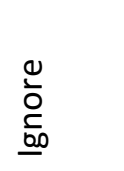 & 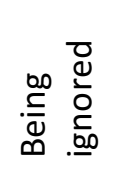 & $\vec{E}$ & 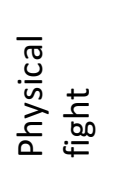 & 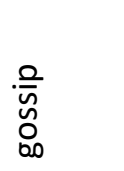 & 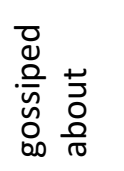 & $\begin{array}{l}\frac{0}{\frac{0}{0}} \\
\frac{3}{y} \\
\frac{x}{4}\end{array}$ & 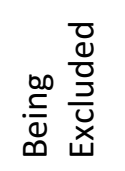 & 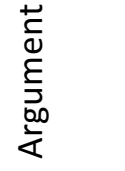 & 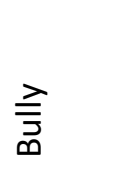 & 恕 \\
\hline Help others & 1 & & & & & & & & & & & \\
\hline Ignore & $\begin{array}{l}.09 \\
\end{array}$ & 1 & & & & & & & & & & \\
\hline Being ignored & -.09 & .09 & 1 & & & & & & & & & \\
\hline Shy & -.10 & -.21 & .26 & 1 & & & & & & & & \\
\hline Physical fight & -.27 & .28 & $-.50 * *$ & .00 & 1 & & & & & & & \\
\hline Gossip & .43 & .13 & .20 & .18 & -.10 & 1 & & & & & & \\
\hline Gossiped about & .00 & $-.49 * *$ & -.21 & .28 & -.05 & .31 & 1 & & & & & \\
\hline Exclude & .11 & .30 & -.44 & -.34 & .38 & -.03 & -.27 & 1 & & & & \\
\hline Being Excluded & -.05 & -.14 & .46 & .22 & -.17 & -.09 & -.15 & $-.63 * *$ & 1 & & & \\
\hline Argument & .31 & $.58^{* *}$ & -.09 & $-.51 * *$ & .25 & .21 & -.21 & -.02 & .04 & 1 & & \\
\hline Bully & .16 & .40 & -.20 & -.31 & $.52^{* *}$ & .32 & -.19 & .39 & -.35 & .41 & 1 & \\
\hline Being Bullied & .07 & .15 & .36 & .17 & -.08 & .00 & -.22 & $-.54 * *$ & $.71 * * *$ & .28 & -.24 & 1 \\
\hline
\end{tabular}


Table S2

\begin{tabular}{|c|c|c|c|c|c|c|}
\hline & helping & shy & bullies & bullied & gossips & gossiped \\
\hline Closeness & $\begin{array}{l}-.011 \\
(-.106, .084)\end{array}$ & $\begin{array}{l}.019 \\
(-.064, .101)\end{array}$ & $\begin{array}{l}.005 \\
(-.084, .094)\end{array}$ & $\begin{array}{l}.012 \\
(-.062, .086)\end{array}$ & $\begin{array}{l}-.012 \\
(-.095, .071)\end{array}$ & $\begin{array}{l}.001 \\
(-.079, .081)\end{array}$ \\
\hline Betweenness & $\begin{array}{l}.029 \\
(-.061, .119)\end{array}$ & $\begin{array}{l}-.039 \\
(-.116, .039)\end{array}$ & $\begin{array}{l}-.067 \\
(-.151, .017)\end{array}$ & $\begin{array}{l}-.037 \\
(-.107, .033)\end{array}$ & $\begin{array}{l}-.057 \\
(-.136, .021)\end{array}$ & $\begin{array}{l}-.079^{*} \\
(-.155,-.003)\end{array}$ \\
\hline Eigenvector & $\begin{array}{l}.223^{* \star \star} \\
(.127, .319)\end{array}$ & $\begin{array}{l}-.378^{* * *} \\
(-.461,-.295)\end{array}$ & $\begin{array}{l}.059 \\
(-.031, .149)\end{array}$ & $\begin{array}{l}-.327^{\star * *} \\
(-.402,-.252)\end{array}$ & $\begin{array}{l}.208^{* * \star} \\
(.124, .292)\end{array}$ & $\begin{array}{l}-.240^{\star \star \star} \\
(-.321,-.158)\end{array}$ \\
\hline Age & $\begin{array}{l}-.002 \\
(-.090, .086)\end{array}$ & $\begin{array}{l}-.038 \\
(-.114, .038)\end{array}$ & $\begin{array}{l}.007 \\
(-.075, .090)\end{array}$ & $\begin{array}{l}-.018 \\
(-.087, .050)\end{array}$ & $\begin{array}{l}.002 \\
(-.074, .079)\end{array}$ & $\begin{array}{l}.003 \\
(-.071, .077)\end{array}$ \\
\hline Gender & $\begin{array}{l}-.246^{* * *} \\
(-.333,-.159)\end{array}$ & $\begin{array}{l}-.152^{* * *} \\
(-.227,-.077)\end{array}$ & $\begin{array}{l}.250^{* * *} \\
(.169, .331)\end{array}$ & $\begin{array}{l}.027 \\
(-.040, .095)\end{array}$ & $\begin{array}{l}-.454^{* * *} \\
(-.529,-.378)\end{array}$ & $\begin{array}{l}-.200^{\star * *} \\
(-.274,-.127)\end{array}$ \\
\hline Constant & $\begin{array}{l}.044 \\
(-.042, .129)\end{array}$ & $\begin{array}{l}-.066 \\
(-.141, .008)\end{array}$ & $\begin{array}{l}-.010 \\
(-.090, .070)\end{array}$ & $\begin{array}{l}-.103^{\star *} \\
(-.169,-.036)\end{array}$ & $\begin{array}{l}-.003 \\
(-.078, .071)\end{array}$ & $\begin{array}{l}-.100^{\star \star} \\
(-.172,-.028)\end{array}$ \\
\hline
\end{tabular}

\begin{tabular}{|c|c|c|c|c|c|}
\hline & argument & physical & ignored & excluded & cooperative \\
\hline Closeness & $\begin{array}{l}.029 \\
(-.061, .118)\end{array}$ & $\begin{array}{ll}-002 & \\
(-.086, & .082)\end{array}$ & $\begin{array}{l}.028 \\
(-.050, .106)\end{array}$ & $\begin{array}{l}.001 \\
(-.076, .078)\end{array}$ & $\begin{array}{ll}-002 & \\
(-094 & 090)\end{array}$ \\
\hline Betweenness & $\begin{array}{l}-.044 \\
(-.129, .041)\end{array}$ & $\begin{array}{l}-.056 \\
(-.136, .023)\end{array}$ & $\begin{array}{l}-.025 \\
(-.098, .047)\end{array}$ & $\begin{array}{l}-.036 \\
(-.106, .034)\end{array}$ & $\begin{array}{l}.039 \\
(-.048, .126)\end{array}$ \\
\hline Eigenvector & $\begin{array}{l}-.024 \\
(-.115, .067)\end{array}$ & $\begin{array}{l}.093^{*} \\
(.008, .178)\end{array}$ & $\begin{array}{l}-.377^{* * *} \\
(-.455,-.299)\end{array}$ & $\begin{array}{l}-.356^{\star * \star} \\
(-.431,-.282)\end{array}$ & $\begin{array}{l}.286^{* * *} \\
(.193, .379)\end{array}$ \\
\hline Age & $\begin{array}{l}-.002 \\
(-.085, .081)\end{array}$ & $\begin{array}{l}.018 \\
(-.060, .096)\end{array}$ & $\begin{array}{l}-.014 \\
(-.086, .059)\end{array}$ & $\begin{array}{l}-.015 \\
(-.089, .058)\end{array}$ & $\begin{array}{l}-.026 \\
(-.111, .059)\end{array}$ \\
\hline Gender & $\begin{array}{l}.090^{*} \\
(.008, .172)\end{array}$ & $\begin{array}{l}.418^{* * *} \\
(.341, .495)\end{array}$ & $\begin{array}{l}-.013 \\
(-.083, .057)\end{array}$ & $\begin{array}{l}.007 \\
(-.061, .074)\end{array}$ & $\begin{array}{l}-.140^{* *} \\
(-.224,-.056)\end{array}$ \\
\hline Constant & $\begin{array}{l}-.046 \\
(-.127, .035)\end{array}$ & $\begin{array}{l}-.010 \\
(-.086, .065)\end{array}$ & $\begin{array}{l}-.093^{*} \\
(-.164,-.022)\end{array}$ & $\begin{array}{l}-.106^{\star \star} \\
(-.177,-.034)\end{array}$ & $\begin{array}{l}.061 \\
(-.021, .144)\end{array}$ \\
\hline
\end{tabular}


Table S3 Correlations matrix for group size attributes.

\begin{tabular}{|c|c|c|c|c|c|c|}
\hline & $\begin{array}{l}\frac{\vec{t}}{n} \\
\frac{1}{0} \\
0\end{array}$ & $\begin{array}{l}\bar{\Phi} \\
\stackrel{ \pm}{ \pm} \\
\frac{\sigma}{0} \\
\frac{.0}{0}\end{array}$ & 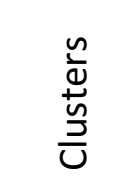 & $\frac{\frac{1}{0}}{\frac{0}{0}} \stackrel{0}{\frac{0}{ \pm}}$ & & $\begin{array}{l}9 \\
\end{array}$ \\
\hline Density & 1.00 & & & & & \\
\hline Diameter & 0.28 & 1.00 & & & & \\
\hline Clusters & $-0.55^{* *}$ & $-0.49 *$ & 1.00 & & & \\
\hline Gender ratio & $0.61^{* *}$ & -0.01 & -0.20 & 1.00 & & \\
\hline Age & 0.05 & 0.16 & -0.24 & -0.02 & 1.00 & \\
\hline Group size & $-0.62 * *$ & -0.01 & $0.57^{*}$ & -0.35 & -0.19 & 1.00 \\
\hline
\end{tabular}


Social Cohesion Social Capital

Table S4. Individual level statistics: Results of multiple logistic regressions with generalized trust as dependent variable

\begin{tabular}{|c|c|}
\hline & Trust \\
\hline Eigenvector & $\begin{array}{l}-.069 \\
(-.171, .033)\end{array}$ \\
\hline Betweenness & $\begin{array}{l}-.003 \\
(-.098, .092)\end{array}$ \\
\hline Closeness & $\begin{array}{l}.081 \\
(-.026, .188)\end{array}$ \\
\hline Age & $\begin{array}{l}.095 \\
(-.010, .199)\end{array}$ \\
\hline Gender & $.145^{* *}(.052, .237)$ \\
\hline Constant & $\begin{array}{l}-.002 \\
(-.104, .100)\end{array}$ \\
\hline \multicolumn{2}{|c|}{$\begin{array}{l}\text { Logistic regression models included age, gender } \\
(1=\text { male, } 0=\text { female) and individual network level } \\
\text { metrics as independent variables. unstandardized } \\
\beta \text { 's are reported. Note. }{ }^{*} p<.05 ;{ }^{* *} p<.01 \text {. }\end{array}$} \\
\hline
\end{tabular}




\section{Individual level metrics, preference \& popularity}

Finally, to get a sense of how the reported centrality measures relate to sociometric measures often used in the peer relationship literature, we have compared them to the more traditional measures of social preference and perceived popularity. Preference was based the total like nominations by the other members of the peer group; perceived popularity was based on the total number of popular nominations. Using total number of positive nominations yielded the same results as using difference scores (e.g. total likes minus total dislikes or total popular minus total unpopular nomination). These analyses allowed us to further embed our current findings in the existing peer relationships literature.

First, replicating earlier studies ${ }^{14}$ we found that there was a weak but significant positive correlation between sociometric and perceived popularity $(\mathrm{r}=.28, \mathrm{p}<.01)$. More importantly, we found that the centrality measures are related to the traditional popularity measures (see Table 5). First, eigenvector centrality was correlated with both sociometric and perceived popularity. As expected, individuals who are more liked, and those who are perceived to be more popular take up important positions within the social network (more towards the top of the hierarchy). A similar finding, but slightly weaker, emerged for the relation between closeness centrality. Interestingly, betweenness centrality showed a positive correlation with sociometric popularity and a trending negative relation with perceived popularity. Thus, those individuals who have a key role in connecting different parts of the network are liked a lot but are not necessarily perceived to be popular and were even slightly perceived to be unpopular (trending $p=.07$ ). Note, that the three metrics are all associated, in different ways, with age and gender (Table 5). Overall the findings suggest that boys take up more 'important' network positions, and that these positions also are related to older ages (i.e. the older the more important). To conclude, the network metrics are able to capture unique variance of social preference and perceived popularity, but, consistent with previous literature ${ }^{61}$, the levels of explained variance also suggest that centrality measures capture independent dimensions of social position. 
Table S5. Results of multiple logistic regressions with individual network metrics

\begin{tabular}{|c|c|c|c|}
\hline & $\begin{array}{l}\text { Eigenvector } \\
\text { (1) }\end{array}$ & $\begin{array}{c}\text { Betweenness } \\
\text { (2) }\end{array}$ & $\begin{array}{c}\text { Closeness } \\
\text { (3) }\end{array}$ \\
\hline Preference & $\begin{array}{l}.440^{* *} \\
(.367, .512)\end{array}$ & $\begin{array}{l}.249^{* *} \\
(.161, .337)\end{array}$ & $\begin{array}{l}.107^{* *} \\
(.083, .131)\end{array}$ \\
\hline Popularity & $\begin{array}{l}.281^{* *} \\
(.210, .351)\end{array}$ & $\begin{array}{l}-.080 \\
(-.166, .006)\end{array}$ & $\begin{array}{l}.033^{* *} \\
(.009, .056)\end{array}$ \\
\hline Age & $\begin{array}{l}.043 \\
(-.092, .177)\end{array}$ & $\begin{array}{l}.157^{* *} \\
(.040, .274)\end{array}$ & $\begin{array}{l}.090^{*} \\
(.015, .164)\end{array}$ \\
\hline Gender & $\begin{array}{l}.108^{* *} \\
(.039, .177)\end{array}$ & $\begin{array}{l}-.022 \\
(-.106, .062)\end{array}$ & $\begin{array}{l}.029^{*} \\
(.006, .052)\end{array}$ \\
\hline Constant & $\begin{array}{l}.078 \\
(-.071, .228) \\
\end{array}$ & $\begin{array}{l}-.040 \\
(-.158, .078)\end{array}$ & $\begin{array}{l}.273 \\
(-.185, .731)\end{array}$ \\
\hline
\end{tabular}

